\title{
MIRROR WRITING, A NORMAL ATTRIBUTE OR PATHOLOGICAL?
}

Mirror writing, its occurrence in famous people, mechanisms, and pathophysiology, are discussed by a neurologist at the National Hospital for Neurology and Neurosurgery, Queen Square, London, UK. Mirror writing may be transient or longlasting; affect single letters, whole words or passages; and may be spontaneous or elicited. It can accompany neurologic disease, but also occurs in normal people, especially left-handers and in young children when they begin to write. The most celebrated mirror writer was Leonardo de Vinci, a lefthander, whose script was almost always from right to left and in mirror images. Lewis Carroll (pseudonym of Charles Lutwidge Dodgson), author of Alice in Wonderland and Through the Looking-Glass, occasionally wrote in "lookingglass" or mirrored letters. In a report in the journal Brain (1896;19:385-387), Allen FJ, a professor of physiology, describes his facility for mirror writing when using his left hand, and commenting that he did not require vision to mirror-write.

Acquired mirror writing occurs most commonly following cerebrovascular lesions, usually in the left hemisphere and accompanying a right hemiplegia. Writing movements of the right hand, when switched to the left, result in mirror writing, a normal but suppressed phenomenon that is released by certain lesions. Orton, a neurologist specializing in reading disabilities, emphasized the tendency to mirror writing in children with dyslexia. Other hypotheses include a right-left spatial disorientation, and the implication of thalamic mechanisms in patients with essential tremor and Parkinsonism, and also cerebellar disease. One unifying feature of mirror writing is the fact that it is almost always executed with the left hand. It is an attribute normally suppressed and becomes evident as a result of disease. (Schott GD. Mirror writing: Allen's self observations, Lewis Carroll's "looking-glass" letters, and Leonardo da Vinci's maps. Lancet Dec 18/25;354:21582161). (Respond: Dr GD Schott FRCP, The National Hospital for Neurology and Newurosurgery, Queen Square, London WC1N 3BG, UK).

COMMENT. Orton introduced the term "strephosymbolia" (twisted symbols) in reference to congenital word blindness, and characterized by 1) confusion of letters and words (eg. p/q and was/saw): 2) reversal of letters; 3) reading from right to left; and 4) mirror reading and writing. (Orton ST. Specific reading disability - strephosymbolia. IAMA 1928;90:1095-99). He considered the cause to be physiological, not pathological, and related to failure of one hemisphere of the brain to become dominant over the other, a neurological explanation in terms of developmental cerebral organization. The following case report summarized from a book on dyslexia is an unusual example of mirror writing with sudden and unexplained onset in a right-handed schoolboy, its persistence for approximately 6 months, association with subtle neurologic abnormalities, dyscalculia, reading and spelling disabilities, and a sudden and complete remission immediately following recovery from head trauma with symptoms of concussion. (Millichap JG, Millichap, Nancy M. Dyslexia: As the Neurologist and Educator Read It. Springfield, IL, Charles C Thomas, 1986).

This child, aged 11 years, was referred to me for neurologic examination in 1984 because of persistent mirror writing, While attending a Montessori school, in sixth grade, he was asked to write a report on falconry. To the consternation of his teacher, an eight page report was written entirely in mirror writing. Gifted in many areas, with a high IQ he had difficulties in reading, spelling, and math. Neurologic abnormalities included macrocephaly and Babinski signs. EEG showed asymmetry of amplitude and rhythm, lower and slower on left posteriorly. CT scan was normal. The cause of his episode of mirror writing was undetermined. 